\title{
Physico-chemical Properties of Lignin Fractions from Acid Pretreated Corn Stover and their Effects on Enzymatic Hydrolysis of Microcrystalline Cellulose
}

\author{
Haitao Yang, ${ }^{\mathrm{b}}$ Yuhang Zhang, ${ }^{\mathrm{b}}$ Chang Geun Yoo, ${ }^{\mathrm{c}}$ Xianzhi Meng, ${ }^{\mathrm{d}}$ Xiong Chen, ${ }^{\mathrm{a}}$ Arthur \\ J. Ragauskas, ${ }^{*, \mathrm{~d}, \mathrm{e}}$ and Lan Yao *,a,d
}

\begin{abstract}
Lignin has been shown to be a recalcitrance factor in many biomass conversion studies. To better understand the effects of lignin on cellulose conversion, different lignin fractions were extracted from the same dilute acid pretreated corn stover by three sequential isolation methods, namely ethanol extraction, dioxane extraction, and enzyme purification. The physicochemical properties of each lignin fraction including molecular weight distribution, surface area, surface charge, and other structural features varied, depending on the isolation methods. All three lignin fractions had negative surface charges, and ethanol-extracted lignin carried the highest surface charges, followed by dioxane-extracted lignin and cellulase-purified residual lignin. These physicochemical properties of lignin fractions also resulted in different extent of inhibitory effects on enzymatic hydrolysis of microcrystalline cellulose (MCC). Dioxane-extracted lignin exhibited the highest inhibitory effect on glucose release from $M C C$, followed by the cellulase-purified residual lignin fraction and ethanol-extracted lignin. Furthermore, lignin fractions with higher contents of syringyl (S) substructure and $\beta-O-4$ aryl ether interunit linkages showed a stronger negative effect on cellulase hydrolysis of MCC.
\end{abstract}

Keywords: Lignin isolation; physico-chemical properties; Corn stover; Cellulase; Avicel

Contact information: a: Key Laboratory of Fermentation Engineering (Ministry of Education), College of Bioengineering, Hubei University of Technology, 28th of Nanli Road, Wuhan 430068, China; b: Hubei Provincial Key Laboratory of Green Materials for Light Industry, Hubei University of Technology, Wuhan 430068, China; c: Department of Paper and Bioprocess Engineering, State University of New York College of Environmental Science and Forestry, Syracuse, NY 13210, USA; d: Department of Chemical and Biomolecular Engineering, The University of Tennessee, Knoxville, TN 37996-2200, USA; e: Department of Forestry, Wildlife and Fisheries, Center for Renewable Carbon, The University of Tennessee, Institute of Agriculture, Knoxville, TN 37996-2200, USA; *Corresponding authors: Tel.: +1 865974 2042;

*Corresponding authors: aragausk@utk.edu; yaolislan1982@aliyun.com

\section{INTRODUCTION}

Lignocellulosic biomass is an attractive, sustainable feedstock for the production of second-generation bioethanol (Samuel et al. 2010). Biomass pretreatment, enzyme hydrolysis, fermentation, and distillation/purification are the four main steps in the bioconversion of lignocellulosics to biofuels (Yang et al. 2016). Pretreatment of biomass under elevated pressure and/or temperature with the addition of acid or base reduces the recalcitrance of biomass and increases the accessibility of cellulose to cellulase, helping achieve high glucose yield for the subsequent fermentation process ( $\mathrm{Pu}$ et al. 2008; Meng et al. 2013; Ertas et al. 2014; Lai et al. 2019a). 
Among various pretreatment methods, dilute acid (DA) pretreatment is one of the leading and widely studied techniques due to its effectiveness, low energy input, and wide applications for a variety of biomass resources (Chen et al. 2011; Teramura et al. 2015). The DA pretreatment solubilizes hemicelluloses, and the remaining acid-insoluble residue is mainly composed of cellulose and lignin (Cao et al. 2012). Although DA pretreatment increases sugar release of the pretreated biomass (Mosier et al. 2005; Hendriks and Zeeman 2009; Yao et al. 2010), the lignin in the solid residue still has inhibitory effects on the subsequent enzymatic hydrolysis process (Yao et al. 2017).

Lignin, the most abundant non-carbohydrate biopolymer in the plant cell wall, is typically composed of syringyl $(\mathrm{S})$, guaiacyl $(\mathrm{G})$, or $p$-hydroxyphenyl $(\mathrm{H})$ units. The composition of lignin in plants varies depending on its species. For instance, softwood is of primarily G-type, hardwood is of a G-S type, and herbaceous crops are of G-S-H type in its lignin. In recent years, the inhibitory effects of various types of lignin on enzymatic hydrolysis, in particular, non-productive adsorption of cellulase onto lignins, have been reported (Yu et al. 2014; Li et al. 2016; Sun et al. 2016; Yoo et al. 2017; Yao et al. 2018a,b; Lai et al. 2018). Lignin forms droplets on the surface of residual biomass under severe acidic pretreatment conditions (e.g., DA pretreatment at and above $130{ }^{\circ} \mathrm{C}$ ), thereby hindering the enzymatic digestion of biomass (Selig et al. 2007). After incubating with lignin isolated from hot water pretreated hardwoods, 2 to $18 \%$ of the initial $\beta$ glucosidase and 50 to $60 \%$ of cellobiohydrolase and endoglucanase activities were retained (Ko et al. 2015). The increase of pretreatment severities results in lignin samples with higher cellulase adsorption ability. Similarly, Lu et al. (2016) reported that electrostatic interactions and hydrophobicity were the main cause of cellulase adsorption to hot-water pretreated lignin. Interestingly, certain organosolv lignins or lignosulfonates enhance the performance of enzymatic hydrolysis, and the effect of lignin on cellulase during enzymatic hydrolysis is a function of both hydrophobic interactions and electrostatic repulsions (Huang et al. 2017; Lai et al. 2019b).

Recently, lignin fractions isolated from dilute acid pretreated Broussonetia papyrifera were used to study the impact of the structural properties of lignin on cellobiohydrolases I adsorption (Yao et al. 2017). Similar studies were conducted with different lignocellulosic substrates such as switchgrass and poplar (Yao et al. 2018a,b). Besides lignin composition, the variety of interunit linkages and hydroxyl group content, surface area and surface charge of lignin affecting cellulase adsorption were studied (Nakagame et al. 2011; Lou et al. 2013). Despite these recent efforts, the mechanism of lignin inhibition on cellulase hydrolysis is still not fully understood. This is due, in part, to lignin's complexity and heterogeneity. Herein, three different lignin fractions were isolated from the dilute acid pretreated corn stover. Lignin composition, structural features, zeta potential, surface area and molecular weights of each lignin fraction were investigated. The effects of these lignin properties with their inhibitory on enzymatic hydrolysis of MCC were also investigated.

\section{EXPERIMENTAL}

\section{Materials}

Corn stover was provided by a local farmer from En shi, Hubei province, China. The chemical composition of the corn stover was $17.6 \%$ Klason lignin, $32.2 \%$ cellulose, $27.6 \%$ hemicellulose, $6.58 \%$ benzene-ethanol extractives, and $13.9 \%$ ash. Cellulase (Sino 
EnzymesR) was a kind gift from Baiyin Sainuo Technology Ltd (Baiyin, PR China), with filter paper activity of $160 \mathrm{U} / \mathrm{g}$ and $\beta$-glucosidase activity of $42 \mathrm{U} / \mathrm{g}$.

Pretreatment

Corn stover was Wiley-milled (screen size of $2 \mathrm{~mm}$ ), extracted with toluene/ethanol $(2: 1, \mathrm{v} / \mathrm{v})$ for $8 \mathrm{~h}$, and then air-dried. The extractive-free corn stover was loaded with a $0.5 \% \mathrm{H}_{2} \mathrm{SO}_{4}$ solution (solid-to-liquid ratio of 1:20 (w/w)) to a one-liter rotary electrothermal pressure digester (ZQS-3, Qinggong Jixie factory of Shanxi University of Science and Technology, Xianyang, Shanxi province, PR China) at $170{ }^{\circ} \mathrm{C}$ for $60 \mathrm{~min}$ (Yao et al. 2010). After the pretreatment, the residual solid was separated by filtration and washed with deionized water until the effluent was $\mathrm{pH}$ neutral, and the solid residue was stored in a sealed bag at $4{ }^{\circ} \mathrm{C}$ prior to further testing. After pretreatment, the chemical composition of corn stover was $60.2 \%$ cellulose, $7.23 \%$ hemicellulose and $24.9 \%$ of lignin.

\section{Methods}

\section{Fractionation of lignin from pretreated corn stover}

Lignin was isolated from the dilute acid pretreated corn stover by three sequential methods in a previous study with some modifications, as shown in Fig. 1 (Yao et al. 2017). The air-dried pretreated corn stover was extracted twice at room temperature with ethanol $(10 \mathrm{~mL} / \mathrm{g}$ biomass $)$ for $24 \mathrm{~h}(2 \times 24 \mathrm{~h})$ with a magnetic stirrer. The collected extract was rotary-evaporated and freeze-dried to yield the crude lignin (NO.1). A dioxane-water mixture $(96: 4, \mathrm{v} / \mathrm{v} ; 10 \mathrm{~mL} / \mathrm{g}$ biomass) was then used to extract the NO.2 lignin from the residue solid after ethanol extraction. These lignins were further purified according to the purification method of milled wood lignin (MWL) (Björkman 1956).

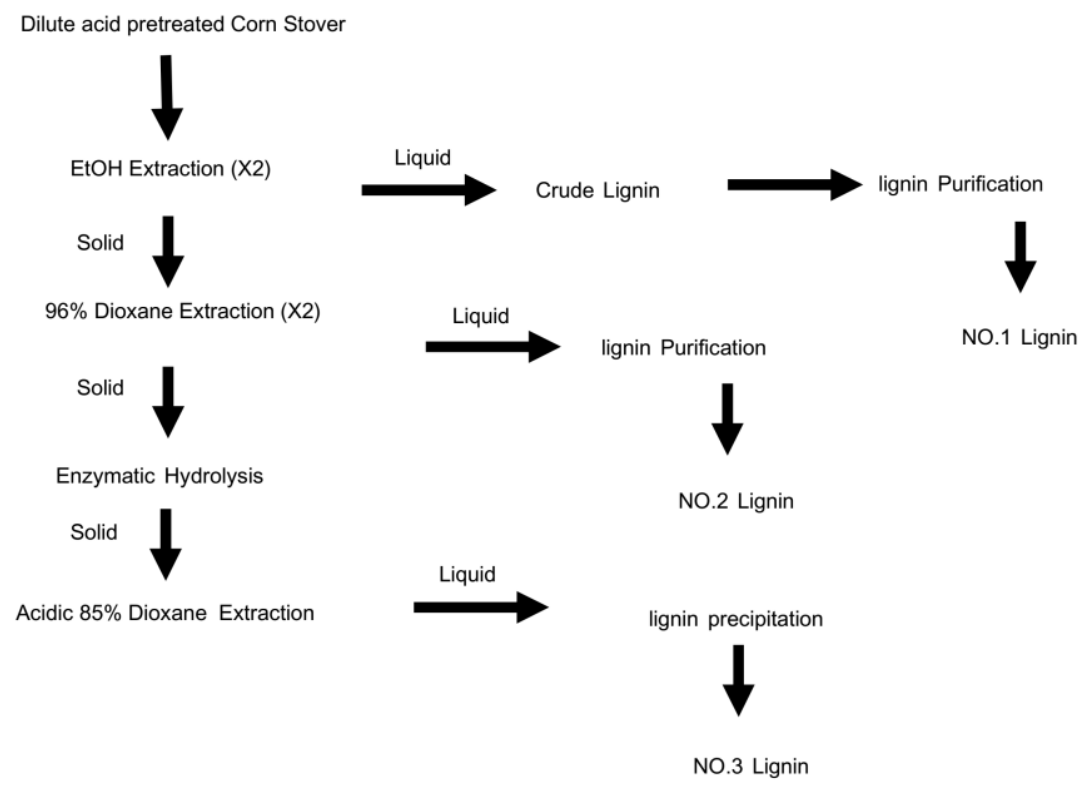

Fig. 1. Isolation process of lignin fractions

The solid residue after the two-step extraction was air-dried and hydrolyzed by overloaded cellulase. The lignin-enriched solid residue after the enzymatic hydrolysis was extracted by acidic $85 \%$ dioxane $(98.6 \mathrm{mg}$ of $37 \%$ hydrochloric acid were mixed with $100 \mathrm{ml}$ of dioxane-water mixture) for $2 \mathrm{~h}$ (Wu and Argyropoulos 2003). The solid 
was washed with acidic $85 \%$ dioxane, and the collected extraction liquid and washings were neutralized with anhydrous sodium carbonate and then rotary-evaporated to reduce the volume. The purified NO.3 lignin was precipitated in acidic water $(\mathrm{pH} 2)$, centrifuged, and freeze-dried. The purity of each isolated lignin fractions is shown in Table 1.

Table 1. Purity of the Isolated Lignin Fractions

\begin{tabular}{cccccc}
\hline & Klason lignin (\%) & Glucan (\%) & Arabinan (\%) & Galactan (\%) & Total (\%) \\
\hline NO.1 lignin & 94.4 & 1.92 & 0.13 & 0.11 & 96.6 \\
NO.2 lignin & 98.7 & 1.82 & 0.20 & 0.05 & 100.7 \\
NO.3 lignin & 98.0 & 0.51 & 0.23 & 0.05 & 98.8 \\
\hline
\end{tabular}

\section{Lignin characterization}

The surface area of lignin fractions was determined by the nitrogen adsorption method. The adsorption/desorption isotherms of nitrogen at $77 \mathrm{~K}$ were measured using a BELSORP mini-II surface area and pore size analyzer (MicrotracBEL, Japan; Nakagame et al. 2011). The zeta potential of lignin was measured at $25^{\circ} \mathrm{C}$ in sodium acetate-acetic acid (NaAc-HAc) buffer (0.05 M, pH 4.8) using a Zeta Potential Analyzer (Zeta plus, Brookhaven, USA) (Lou et al. 2013). Lignin was also subjected to Fourier-transform infrared (FTIR) spectroscopy analysis (Spectrum One FTIR system, Perkin Elmer, Wellesley, MA) from 4000 to $500 \mathrm{~cm}^{-1}$.

Lignin and carbohydrate contents were determined by the National Renewable Energy Laboratory (NREL) procedure using high performance liquid chromatography (HPLC) (Shimadzu, Kyoto, Japan). Gel permeation chromatography (GPC) analysis was conducted to determine the molecular weights of lignin fractions after acetylation. Tetrahydrofuran (THF) was used as eluent, and the flow rate was $1.0 \mathrm{~mL} / \mathrm{min}$. Different sizes of polystyrene standards were used as calibration standards.

Two-dimensional (2D) ${ }^{1} \mathrm{H}-{ }^{13} \mathrm{C}$ heteronuclear single quantum coherence (HSQC) NMR experiment was conducted at $298 \mathrm{~K}$ using a Bruker Avance III 400-MHz spectroscopy with a 5-mm Broadband Observe probe $(5-\mathrm{mm}$ BBO $400 \mathrm{MHz}$ with Zgradient probe, Bruker, Karlsruhe, Germany). The analysis was conducted with a Bruker standard pulse sequence ('hsqcetgpsi2'), spectral width of $11 \mathrm{ppm}$ in F2 $\left({ }^{1} \mathrm{H}\right)$ with 2048 data points and $190 \mathrm{ppm}$ in $\mathrm{F} 1\left({ }^{13} \mathrm{C}\right)$ with 256 data points, 96 scans, and 1-s delay.

\section{Cellulase hydrolysis of microcrystalline cellulose with the addition of different lignin fractions}

Prior to the cellulase hydrolysis, microcrystalline cellulose (MCC) having the brand name Avicel was pretreated to increase digestibility by $\mathrm{NaOH}$ (Du et al. 2018). Enzymatic hydrolysis of pretreated MCC was performed in $500 \mathrm{~mL}$ of sodium citrate buffer $(50 \mathrm{mM}, \mathrm{pH} 4.8)$ with $2 \%$ (w/v) substrate loading at $50{ }^{\circ} \mathrm{C}$ and $150 \mathrm{rpm}$ for $72 \mathrm{~h}$. The enzyme loading of cellulase was 25 FPU/g glucan. To investigate the effects of each lignin fraction on enzymatic hydrolysis, $500 \mathrm{mg}$ lignin was physically mixed with 500 $\mathrm{mg}$ pretreated MCC. Glucose concentration in the hydrolysate was determined by HPLC (Shimadzu, Kyoto, Japan) with a refractive index detector (Shimadzu) on an Aminex HPX-87P column (Bio-Rad, Hercules, CA, USA) running at a flow rate of $0.6 \mathrm{~mL} / \mathrm{min}$ at $65^{\circ} \mathrm{C}$, with water as the eluent. 


\section{RESULTS AND DISCUSSION}

\section{Inhibitory Effect of Lignins on Cellulase Hydrolysis}

The inhibitory effects of lignin on enzymatic hydrolysis of cellulose were evaluated with different lignin fractions from dilute acid pretreated corn stover and $\mathrm{NaOH}$ pretreated $\mathrm{MCC}$ as a standard cellulose resource. As Fig. 2 presents, negative effects were observed from all three lignins (Fig. 2). The hydrolysis yield of pretreated MCC after $72 \mathrm{~h}$ decreased from $70.3 \%$ (control) to $41.3 \%, 33.6 \%$, and $39.1 \%$ with NO.1, NO.2, and NO.3 lignins, respectively. The results indicated that the NO.2 lignin had the most inhibition impact (52.2\% decrease of glucose release). NO.1 and NO.3 lignins had comparable inhibition effects on glucose release from MCC, with a 41 to $44 \%$ decrease. This inhibition could be attributed to several factors, such as the non-productive binding of cellulase to lignin that is largely governed by hydrophobic interactions, hydrogen bonding, and electrostatic interactions according to the previous studies (Yoo et al. 2017). Structural features of lignin are essential information to understand these inhibitory effects on enzymatic hydrolysis of pretreated MCC.

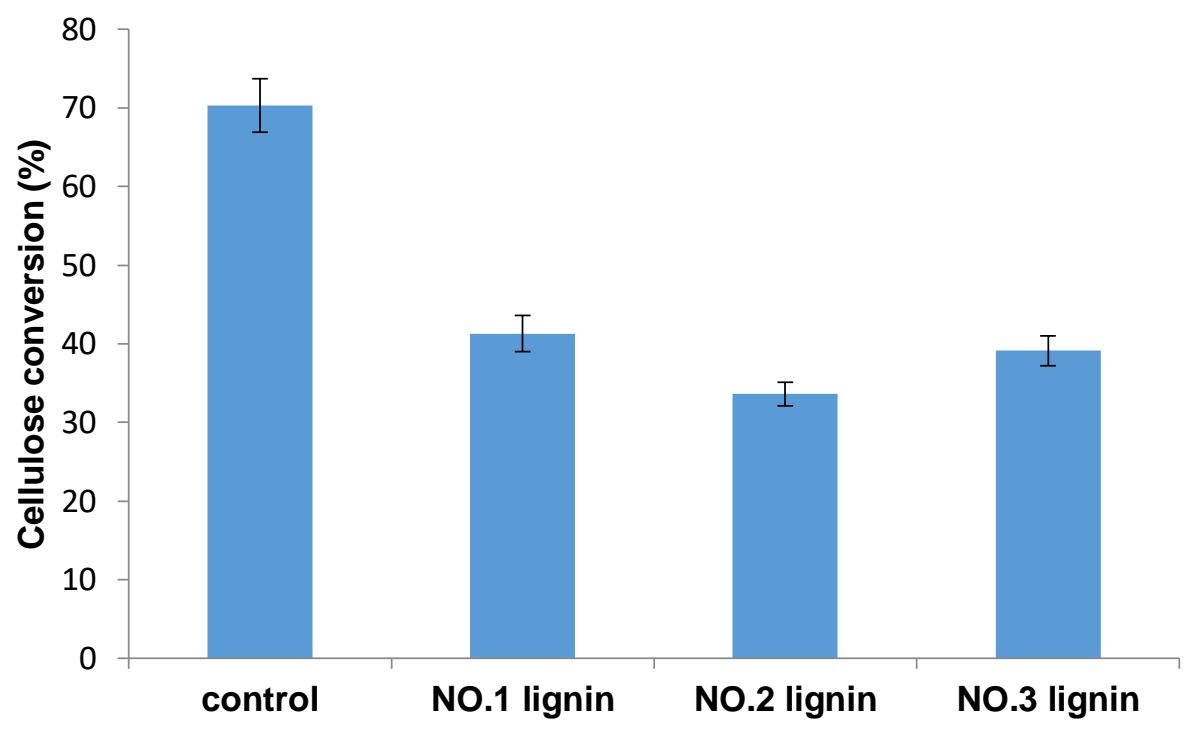

Fig. 2. Cellulose conversion of pretreated MCC with different lignin fractions

\section{Physical Features of Lignin Fractions}

Molecular weight of lignin fractions

The molecular weight distribution of each lignin fraction was analyzed by GPC. The molecular weights $\left(M_{\mathrm{w}}\right.$ : weight-average molecular weight and $M_{\mathrm{n}}$ : number-average molecular weight) and the polydispersity index (i.e., PDI $=M_{\mathrm{w}} / M_{\mathrm{n}}$ ) of each lignin are summarized in Table 2. The results showed that $M_{\mathrm{w}}$ of NO.1, NO.2, and NO.3 lignins were 1810,5990 , and $14450 \mathrm{~g} / \mathrm{mol}$, respectively. The PDI values of these lignin fractions were relatively low $(<1.5)$, indicating that the distribution of molecular weights in these lignin fractions was relatively narrow. Similar to the previous studies, there was no clear relationship between average molecular weights and inhibitory effect of lignin on cellulase hydrolysis (Pareek et al. 2013; Guo et al. 2014). Lower polydispersity is favored for the adsorption of cellulase (Berlin et al. 2006; Guo et al. 2014; Yao et al. 2018a); however, this tendency was not observed in the present study. 
Table 2. Weight-average $\left(M_{\mathrm{w}}\right)$, Number-average $\left(M_{\mathrm{n}}\right)$ Molecular Weights and Polydispersity Indexes $\left(M_{\mathrm{w}} / M_{\mathrm{n}}\right)$ of Different Lignin Fractions

\begin{tabular}{|c|c|c|c|}
\hline & $M_{\mathrm{n}}$ & $M_{\mathrm{w}}$ & PDI $\left(M_{\mathrm{w}} / M_{\mathrm{n}}\right)$ \\
\hline NO.1 lignin & 1260 & 1810 & 1.44 \\
\hline NO.2 lignin & 4010 & 5990 & 1.49 \\
\hline NO.3 lignin & 11880 & 14450 & 1.22 \\
\hline
\end{tabular}

Surface area and surface charge

Surface area is one of the factors that influence the non-productive binding of cellulase to lignin. In this study, the surface area of each lignin fraction was determined by a BET analyzer. The results in Table 3 show that the surface area of lignin fractions was $0.17,0.69$, and $2.87 \mathrm{~m}^{2} / \mathrm{g}$ for NO.1, NO.2 and NO.3 lignins, respectively. However, Fig. 2 shows that NO.2 lignin showed the most inhibitory effect on cellulase hydrolysis of pretreated MCC among the three lignin samples. Other studies have also reported that the maximum protein adsorption capacity was not well correlated with the observed specific surface area and pore size of lignins (Berlin et al. 2006; Nakagame et al. 2011; Pareek et al. 2013).

Zeta potential was used to represent the surface charge of lignin. Table 3 shows that all of the lignin fractions from the pretreated corn stover showed negative zeta potential. NO. 1 lignin exhibited the highest negative surface charge, followed by NO. 2 lignin and NO.3 lignin. As cellulase exhibits a positive charge in the sodium citrate buffer at $\mathrm{pH}$ 4.8, cellulase and lignin could interact by electrostatic interactions (Lou et al. 2013). At $\mathrm{pH} 4.8$, positively charged enzymes (such as Cel6A and Cel5A) were more strongly adsorbed onto the negatively charged lignins compared to negatively charged enzymes, such as Cel7A and Cel7B due to the electrostatic repulsions (Saini et al. 2016; Huang et al. 2017). However, Lou et al. found that the nonspecific binding of cellulase was not significantly affected by surface charge of lignin at $\mathrm{pH} 4.8$ (Lou et al. 2013). In this study, charge of NO.1 lignin was twice the value of NO.3 lignin, but these two lignins showed similar cellulase hydrolysis yields of pretreated MCC.

These results suggested that these structural features of lignin were not significantly involved in the interaction between the cellulases and lignin. Therefore, other chemical characteristics of the lignin fractions were investigated to explore the inactivation mechanism.

Table 3. Surface Area and Surface Charge of Lignin Fractions

\begin{tabular}{|c|c|c|c|}
\hline & NO.1 lignin & NO.2 lignin & NO.3 lignin \\
\hline Surface area/ $\mathrm{m}^{2} / \mathrm{g}$ & 0.17 & 0.69 & 2.87 \\
\hline Surface charge $/ \mathrm{mv}$ & -30.3 & -25.9 & -15.1 \\
\hline
\end{tabular}

\section{Chemical Features}

FT-IR determination

FT-IR is a commonly used tool to analyze the structural features of lignin (Ghaffar and Fan 2013). FT-IR spectra of the lignin fractions are shown in Fig. 3. The assignment of signals was based on the published values (Ghaffar and Fan 2013). The peak near $3420 \mathrm{~cm}^{-1}$ represents $\mathrm{OH}$ stretching. The peak at $1700 \mathrm{~cm}^{-1}$ was ascribed to the unconjugated carbonyl (Kumar et al. 2009). The signals at 1604, 1514, and $1425 \mathrm{~cm}^{-1}$ are assigned to the aromatic ring of each lignin fraction. The shift of band position from 1505 
to $1514 \mathrm{~cm}^{-1}$ is due to condensation reactions during acid pretreatment and/or lignin extraction process (Esteves et al. 2013).

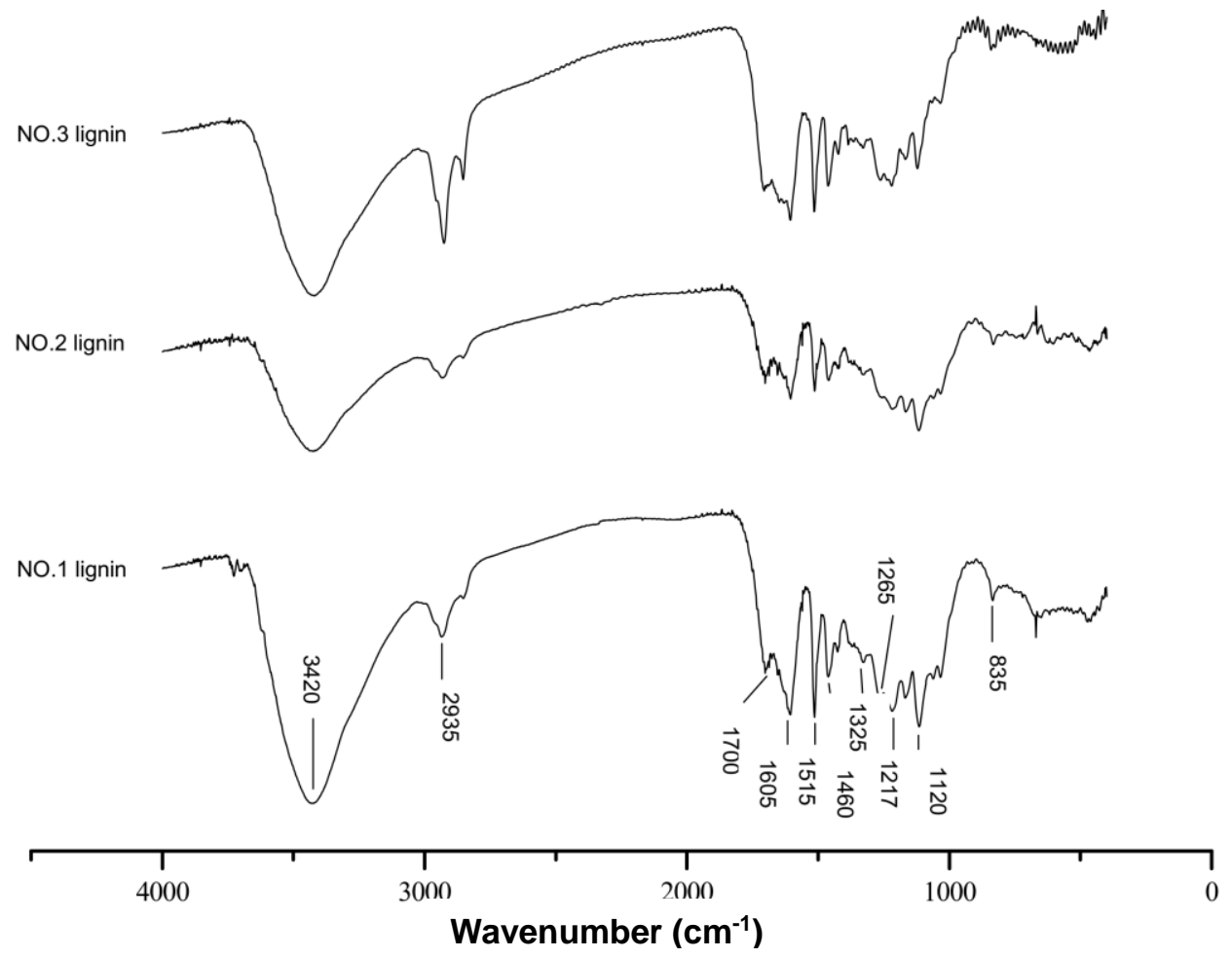

Fig. 3 FT-IR spectra of different lignin fractions

The absorption band position at $2937 \mathrm{~cm}^{-1}$ is attributed to stretching of $-\mathrm{CH},-\mathrm{CH}_{2}$ and $-\mathrm{CH}_{3}$. Signals at 1325,1262 , and $834 \mathrm{~cm}^{-1}$ were assigned to $\mathrm{C}-\mathrm{O}$ bond of syringyl, guaiacyl, and $p$-hydroxyphenyl units (Faix 1991), respectively.

Table 4. Assignment and Relative Intensities of Signals in FT-IR Spectra of Lignin Fraction

\begin{tabular}{|c|c|c|c|c|}
\hline \multirow{2}{*}{ Assignment } & \multirow{2}{*}{ Wavenumber $\left(\mathrm{cm}^{-1}\right)$} & \multicolumn{3}{|c|}{ Relative Intensity } \\
\cline { 3 - 5 } & & NO.1 Lignin & NO.2 lignin & NO.3 Lignin \\
\hline$-\mathrm{OH}$ stretching vibration & 3420 & 1.23 & 1.10 & 1.20 \\
\hline$-\mathrm{CH},-\mathrm{CH}_{2}$ and $-\mathrm{CH}_{3}$ & 2937 & 1.05 & 1.01 & 1.12 \\
\hline $\begin{array}{c}\mathrm{C}=\mathrm{O} \text { stretch in } \\
\text { unconjugated ketone }\end{array}$ & 1700 & 0.93 & 0.94 & 1.02 \\
\hline Aromatic ring & 1604 & 1.00 & 0.98 & 1.03 \\
\hline Aromatic ring & 1514 & 1.00 & 1.00 & 1.00 \\
\hline C-H in -CH & 1.08 & 1.04 & 1.05 \\
\hline Aromatic ring & 1460 & 1.08 & 1.06 & 1.04 \\
\hline Syringyl & 1425 & 1.11 & 1.04 & 0.99 \\
\hline Guaiacyl & 1325 & 1.05 & 1.01 & 0.95 \\
\hline C=O in ester group & 1262 & 0.95 & 1.00 & 0.94 \\
\hline $\begin{array}{c}\text { Aromatic C-H in-plane } \\
\text { deformation }\end{array}$ & 1168 & 0.96 & 1.03 & 0.98 \\
\hline C=O stretching & 1120 & 1.06 & 1.04 & 0.90 \\
\hline$p$-hydroxyphenyl units & 834 & 1.14 & 0.90 & 0.82 \\
\hline
\end{tabular}


In addition, the band at $1168 \mathrm{~cm}^{-1}$ originated from $p$-hydroxyphenyl structures, which indicated that the lignin fractions from dilute acid pretreated corn stover were of the H-S-G type (Sun et al. 2003). The relative signal intensities of various functional groups were calculated as the ratio with reference to the signal intensity of the band at $1514 \mathrm{~cm}^{-1}$ (Table 4) (Guo et al. 2014). The structure of different lignin fractions varied. Syringyl, guaiacyl, and $p$-hydroxyphenyl units were different in the three lignin fractions. As shown in Table 4, stronger intensities of signals at 1262 and $834 \mathrm{~cm}^{-1}$, assigned to guaiacyl and $p$-hydroxyphenyl, were found in NO.2 lignin fraction. To further define the relationship between lignin structure and cellulase interactions, more detailed structural characteristics were needed which was accomplished by NMR.

\section{HSQC determination}

HSQC is a commonly applied NMR technique for the structural analysis of lignin. In this study, HSQC was employed to compare the structural features of each lignin fractions extracted from dilute acid pretreated corn stover. The cross peaks were assigned according to the previous studies (Samuel et al. 2010; Hu et al. 2012; Zeng et al. 2013; Yang et al. 2016). In the aromatic region $(160-90 / 8.0-5.5 \mathrm{ppm}),{ }^{13} \mathrm{C}-{ }^{1} \mathrm{H}$ correlations of all three lignin subunits including $\mathrm{S}, \mathrm{G}$ and $\mathrm{H}$ units were observed. This observation is consistent with the FT-IR analysis. The ${ }^{13} \mathrm{C}-{ }^{1} \mathrm{H}$ correlation for $\mathrm{S}_{2 / 6}$ at $\delta_{\mathrm{C}} / \delta_{\mathrm{H}} 103.4 / 6.7, \mathrm{G}_{2}$ at $\delta_{\mathrm{C}} / \delta_{\mathrm{H}} 111.5 / 6.9, \mathrm{H}_{2 / 6}$ at $\delta_{\mathrm{C}} / \delta_{\mathrm{H}} 128.0 / 7.2$, and $p \mathrm{CA}_{2 / 6}$ at $\delta_{\mathrm{C}} / \delta_{\mathrm{H}}$ $129.9 / 7.4$ were used to semi-quantitatively measure the $\mathrm{S}, \mathrm{G}, \mathrm{H}$ and $p \mathrm{CA}$ contents, respectively. The chemical shifts of $\alpha$-oxidized $\mathrm{S}_{2 / 6}\left(\delta_{\mathrm{C}} / \delta_{\mathrm{H}} 106.5 / 7.3\right)$ and $\mathrm{FA}_{2}\left(\delta_{\mathrm{C}} / \delta_{\mathrm{H}}\right.$ 110.9/7.3) were only found in NO.3 lignin. Cross peaks from condensed $\mathrm{S}_{2 / 6}$ were well resolved at $\delta_{\mathrm{C}} / \delta_{\mathrm{H}} 104.7 / 6.4$, which existed in both NO.1 and NO.2 lignin. Condensed $\mathrm{G}_{2}$ at $\delta_{\mathrm{C}} / \delta_{\mathrm{H}} 112.4 / 6.7$ was only observed in the aromatic region of NO.1 lignin spectra. The correlations of $\mathrm{G}_{5}, \mathrm{G}_{6}, p \mathrm{CA}_{7}$ and $p \mathrm{CA}_{3 / 5}$ were also observed. As shown in Table 5, the composition of each lignin fractions was different. Ethanol-extracted lignin fraction (NO.1) was composed of $10.2 \% \mathrm{H}$ units, $48.6 \% \mathrm{~S}$ (condensed and non-condensed) units and $41.2 \% \mathrm{G}$ (condensed and non-condensed) units. The $\mathrm{S}$ units represented the majority of the other two lignin fractions, which was $88.7 \%$ and $84.0 \%$ in NO.2 and NO.3 lignin, respectively. The overwhelming percentage of S units was also observed in other studies (Chen et al. 2017; Dong et al. 2019). That was due, in part, to more degradation of $\mathrm{G}$ than $\mathrm{S}$ during pretreatment (Chen et al. 2019).

Lignin condensation is commonly observed after the dilute acid pretreatment $(\mathrm{Yu}$ et al.2014). In the present study, condensed S was found in NO.1 and NO.2 lignin, and it accounted for $18.1 \%$ and $13.5 \%$ of the total lignin subunits, respectively. The condensed $\mathrm{G}_{2}$ was only observed in NO. 1 lignin. It is interesting to note that most of the condensed aromatics were isolated by solvent extractions (i.e., ethanol and dioxane), in particular, in NO. 1 lignin fraction. $p C A$ is considered to be exclusively acylated at $\gamma$-position by ester bonds in various herbaceous crops via lignification of $p$-coumarolyated monolignols (Kim and Ralph 2010). The content of $p$ CA increased from $30.8 \%$ in NO.1 lignin to $81.5 \%$ in NO.3 lignin.

The ${ }^{13} \mathrm{C}-{ }^{1} \mathrm{H}$ correlations of methoxyl group $\left(-\mathrm{OCH}_{3}\right)$ and various linkages were observed in the aliphatic region 90-45/6.0-2.0 ppm. The cross peaks corresponding to $\beta$ O-4 were centered at $\delta_{\mathrm{C}} / \delta_{\mathrm{H}} 71.7 / 4.8\left(\mathrm{~A}_{\alpha-\mathrm{S}}\right), 71.1 / 4.7\left(\mathrm{~A}_{\alpha-\mathrm{G}}\right), 83.4 / 4.3\left(\mathrm{~A}_{\beta-\mathrm{G} / \mathrm{H}}\right)$, and $60.5 / 3.6$ $\left(\mathrm{A}_{\gamma}\right)$. The ${ }^{13} \mathrm{C}-{ }^{1} \mathrm{H}$ correlations of phenylcoumaran $(\beta-5)$ were found at $\delta_{\mathrm{C}} / \delta_{\mathrm{H}} 85.9 / 5.5\left(\mathrm{~B}_{\alpha}\right)$, $\delta_{\mathrm{C}} / \delta_{\mathrm{H}} 52.9 / 3.5\left(\mathrm{~B}_{\beta}\right)$ and $62.2 / 3.8\left(\mathrm{~B}_{\gamma}\right)$. Signals from $\mathrm{C}_{\alpha} / \mathrm{H}_{\alpha}$ in $\beta-\mathrm{O}-4$ and $\beta-5$ substructure were used to represent specific total linkages. The results indicated that $\beta-\mathrm{O}-4$ linkages 
dominated the interunit bonds in all lignin fractions, followed by $\beta-5$. The content of lignin interunit linkages, including $\beta-\mathrm{O}-4$ and $\beta-5$, linkages over total aromatic regions was $4.6 \%, 24.1 \%$, and $15.3 \%$ in NO.1, NO.2, and NO.3 lignin fractions, respectively, indicating that NO.2 lignin fraction contained the most amounts of these lignin inter-unit linkages, followed by NO.3 lignin fraction. Furthermore, lignin extracted by dioxane (NO. 2) had more $\mathrm{C}-\mathrm{C}$ bond contents than other fractions.

\section{Relationships between structural properties of lignin and its inhibition on cellulase}

According to the results of the aforementioned characteristics of lignins and their inhibition on enzymatic hydrolysis, the lignin fractions comprising of more $\mathrm{S}$ units resulted in a higher inhibitory impact on cellulase performance $\left(y=-0.14 x+48.55, \mathrm{R}^{2}=\right.$ 0.63), which was consistent with previous study with gramineous crops (Yao et al. $2018 b$ ). The negative effect of the amount of lignin inter-unit linkages (including $\beta-\mathrm{O}-4$ and $\beta-5)\left(y=-0.39 x+43.69, \mathrm{R}^{2}=0.91\right)$ or the $\beta-\mathrm{O}-4\left(y=-0.40 x+43.58, \mathrm{R}^{2}=0.88\right)$ in lignin fraction on glucose yield from pretreated MCC was also observed. The results are consistent with other published results (Goujon et al. 2003; Xu et al. 2012; Jiang et al. 2016). These HSQC results indicated that the $\mathrm{S} / \mathrm{G}$ ratio is a negative factor, whereas the $\mathrm{H} / \mathrm{G}$ could positively affect saccharification process of herbaceous biomass (Xu et al. 2012). The more $S$ units in lignin result in a more linear structure, which could adsorb on the cellulase surface more tightly and decrease the accessibility of cellulose dramatically (Jiang et al. 2016). However, some earlier studies showed that low S/G ratio caused higher affinity between lignin and cellulase (Guo et al. 2014). It was even pointed out that the phenolic $\mathrm{OH}$ group from condensed $\mathrm{G}$ had a strong correlation with their inhibition on glucose release (Sun et al. 2016). The contradictory results obtained from these studies indicated that there might be other lignin properties that had a more profound influence on lignin interaction with cellulase. It is hypothesized that a higher degree of condensation could result in greater cellulase adsorption via hydrophobic interaction (Ko et al. 2015). The degree of condensation (DC) of the isolated three lignin fractions was $0.76,0.58$ and 0.30 , respectively, which was calculated from $3.00-\mathrm{I}_{124-102}$ ppm, based on the ${ }^{13} \mathrm{C}$ NMR spectra (Sun et al. 2016). These results suggest that DC of lignin did not exhibit significant influences on cellulose conversion in this study.

Table 5. Quantitative Information of Three Lignin Samples in the HSQC Spectra

\begin{tabular}{|c|c|c|c|}
\hline \multirow{2}{*}{ Lignin Substructure } & NO.1 Lignin & NO.2 Lignin & NO.3 Lignin \\
\cline { 2 - 4 } & $\%^{\mathrm{a}}$ & $\%^{\mathrm{a}}$ & $\%^{\mathrm{a}}$ \\
\hline Non-condensed S & 30.5 & 75.2 & 84.0 \\
\hline Condensed S & 18.1 & 13.5 & 0.0 \\
\hline Total S & 48.6 & 88.7 & 84.0 \\
\hline Non-condensed G & 0.0 & 3.0 & 6.7 \\
\hline Condensed G & 41.2 & 0 & 0.0 \\
\hline Total G & 41.2 & 3.0 & 6.7 \\
\hline H & 10.2 & 8.3 & 9.2 \\
\hline$p C A$ & 30.8 & 69.9 & 81.5 \\
\hline$\beta-O-4$ & 4.1 & 22.6 & 15.1 \\
\hline$\beta-5$ & 0.5 & 1.5 & 0.2 \\
\hline
\end{tabular}

${ }^{a}$ Amount of specific functional group was expressed as percentage of $\mathrm{S}+\mathrm{G}+\mathrm{H}$

Studies on wheat straw obtained by soda-AQ and kraft pretreatments indicated that residual lignin containing less $\beta-\mathrm{O}-4$ subunits released more glucose during cellulase 
hydrolysis process (Yang et al. 2016). A negative correlation was found between the content of $\beta-\mathrm{O}-4$ bonds in hydrothermal pretreated biomass and its inhibition in pretreated MCC hydrolysis (Kellock et al. 2019). In this study, the lignin fraction containing more etherified lignin interunit linkages (NO.2 lignin) also showed more profound inhibitory effect on pretreated MCC saccharification. Earlier studies indicated that chemical modifications produced by pretreatment with laccase and a phenolic mediator resulting in breakdown of the main inter-unit linkages could improve saccharification (Rico et al. 2014).

\section{CONCLUSIONS}

1. Lignin fractions extracted from dilute acid pretreated corn stover showed different physicochemical properties and inhibitory effects on cellulase hydrolysis of the pretreated microcrystalline cellulose (MCC).

2. The structural features of lignin fractions extracted from dilute acid pretreated corn stover influence the interaction between cellulase and lignin based on the analysis. It is hypothesized that lignin with S-type substructure could affect cellulase activity more. Lignin with more lignin interunit linkages, such as $\beta-\mathrm{O}-4$ and $\beta-5$ linkages, exhibited greater significant inhibitory effect on glucose release from the pretreated MCC.

\section{ACKNOWLEDGMENTS}

The authors are grateful for the support by National Natural Science Foundation of China (NO. 21978074 and 31871789), China Scholarship Council (NO. 2011842330 and NO. 201508420257) and Key Laboratory of Pulp and Paper Science \& Technology of Ministry of Education of China (NO. KF201611 and NO. KF201719), Key Project of Hubei Provincial Department of Education (NO. D20161402), and Foundation of Hubei Provincial Key Laboratory of Green Materials for Light Industry (NO. 201611B01, 201806A02).

\section{REFERENCES CITED}

Berlin, A., Balakshin, M., Gilkes, N., Kadla, J., Maximenko, V., Kubo, S., and Saddler, J. (2006). "Inhibition of cellulase, xylanase and $\beta$-glucosidase activities by softwood lignin preparations," J. Biotechnol. 125, 198-209. DOI: 10.1016/j.jbiotec.2006.02.021

Björkman, A. (1956). "Studies on finely divided wood. Part 1. - Extraction of lignin with neutral solvent," Sven. Papperstidn. 59, 477-485.

Cao, S., Pu, Y., Studer, M., Wyman, C., and Ragauskas, A. J. (2012). “Chemical transformations of Populus trichocarpa during dilute acid pretreatment," RSC Advances 2, 10925-10936. DOI: 10.1039/C2RA22045H

Chen, W., Pen, B., Yu, C., and Hwang, W. (2011). "Pretreatment efficiency and structural characterization of rice straw by an integrated process of dilute-acid and 
steam explosion for bioethanol production," Bioresource Technol. 102, 2916-2924. DOI: 10.1016/j.biortech.2010.11.052

Chen, L., Dou, J., Ma, Q., Li, N., Wu, R., Bian, H., Yelle, D.J., Vuorinen, T., Fu, S., and Pan, X. (2017). "Rapid and near-complete dissolution of wood lignin at $<80{ }^{\circ} \mathrm{C}$ by a recyclable acid hydrotrope," Sci. Adv. 3, e1701735. DOI: 10.1126/sciadv.1701735

Chen, Z., Jacoby, W., and Wan, C. (2019). "Ternary deep eutectic solvents for effective biomass deconstruction at high solids and low enzyme loadings," Bioresource Technol. 279, 281-286. DOI: 10.1016/j.biortech.2019.01.126

Dong, C., Meng, X., Shun, Y., Tse, H., Ragauskas A., and Leu S. (2019). "Diol pretreatment to fractionate a reactive lignin in lignocellulosic biomass biorefineries," Green Chem. 21, 2788-2800. DOI: 10.1039/C9GC00596J

Du, J., Zhang, X., Li, X., Zhao, J., Liu, G., Gao, B., and Qu, Y. (2018). “The cellulose binding region in Trichoderma reesei cellobiohydrolase I has a higher capacity in improving crystalline cellulose degradation than that of Penicillium oxalicum," Bioresource Technol. 266, 19-25. DOI: 10.1016/j.biortech.2018.06.050

Esteves, B., Marques, A., Domingos, I., and Pereira, H. (2013). "Chemical changes of heat treated pine and eucalypt wood monitored by FTIR," Ciencia y Tecnología 15(2), 245-258. DOI: 10.4067/S0718-221X2013005000020

Ertas, M., Han, Q., and Jameel, H. (2014). "Acid-catalyzed autohydrolysis of wheat straw to improve sugar recovery," Bioresource Technol. 169, 1-8. DOI:

10.1016/j.biortech.2014.06.081

Faix, O. (1991). "Classification of lignins from different botanical origins by FT-IR spectroscopy," Holzforschung 45, 21-27. DOI:10.1515/hfsg.1991.45.s1.21

Ghaffar, S., and Fan, M. (2013). "Structural analysis for lignin characteristics in biomass straw,” Biomass Bioenergy 57, 264-279. DOI: 10.1016/j.biortech.2014.06.081

Goujon, T., Ferret, V., Mila, I., Pollet, B., Ruel, K., Burlat, V., Joseleau, J., Barriere, Y., Lapierre, C., and Jouanin, L. (2003). "Down-regulation of the AtCCR1 gene in Arabidopsis thaliana: Effects on phenotype, lignins and cell wall degradability," Planta 217, 218-228. DOI: 10.2307/23387842

Guo, F., Shi, W., Sun, W., Li, X., Wang, F., Zhao, J., and Qu, Y. (2014). 'Differences in the adsorption of enzymes onto lignins from diverse types of lignocellulosic biomass and the underlying mechanism," Biotechnol. Biofuels 7, 38-47. DOI: 10.1186/17546834-7-38

Hendriks, A., and Zeeman, G. (2009). "Pretreatments to enhance the digestibility of lignocellulosic biomass," Bioresource Technol. 100, 10-18. DOI: 10.1016/j.biortech.2008.05.027

Hu, G., Cateto, C., Pu, Y., Samuel, R., and Ragauskas, A. (2012). 'Structural characterization of switchgrass lignin after ethanol organosolv pretreatment," Energy Fuels 26, 740-745. DOI: 10.1021/ef201477p

Huang, Y., Sun, S., Huang, C., Yong, Q., Elder, T., and Tu, M. (2017). "Stimulation and inhibition of enzymatic hydrolysis by organosolv lignins as determined by zeta potential and hydrophobicity," Biotechnol Biofuels 10, 162-172. DOI: 10.1186/s13068-017-0853-6

Jiang, B., Wang, W., Gu, F., Cao, T., and Jin, Y. (2016). "Comparison of the substrate enzymatic digestibility and lignin structure of wheat straw stems and leaves pretreated by green liquor," Bioresource Technol. 199,181-187. DOI: 10.1016/j.biortech.2015.08.104 
Kellock, M., Maaheimo, H., Marjamaa, K., Rahikainen, J., Zhang, H., HolopainenMantila, U., Ralph, J., Tamminen, T., Felby, C., and Kruus, K. (2019). "Effect of hydrothermal pretreatment severity on lignin inhibition in enzymatic hydrolysis," Bioresource Technol. 280, 303-312. DOI: 10.1016/j.biortech.2019.02.051

Ko, J., Ximenes, E., Kim, Y., and Ladisch, M. (2015). "Adsorption of enzyme onto lignins of liquid hot water pretreated hardwoods," Biotechnol. Bioeng. 112, 447-456. DOI: $10.1002 /$ bit. 25359

Kim, H., and Ralph, J. (2010). "Solution-state 2D NMR of ball-milled plant cell wall gels in DMSO-d6/pyridine-d5," Org. Biomol. Chem. 8, 576-591. DOI:10.1039/B916070A

Kumar, R., Mago, G., Balan, V., and Wymand, C. (2009). "Physical and chemical characterizations of corn stover and poplar solids resulting from leading pretreatment technologies," Bioresource Technol. 100, 3948-3962. DOI: 10.1016/j.biortech.2009.01.075

Lai, C., Tu, M., Yong, Q., and Yu, S. (2018). "Synergistic effects of pH and organosolv lignin addition on the enzymatic hydrolysis of organosolv-pretreated loblolly pine," RSC Adv. 8, 13835-13841. DOI: 10.1039/C8RA00902C

Lai, C., Jia, Y., Wang, J., Wang, R., Zhang, Q., Chen, L., Shi H., Huang, C., Li, X., and Yong, Q. (2019a). "Co-production of xylooligosaccharides and fermentable sugars from poplar through acetic acid pretreatment followed by poly (ethylene glycol) ether assisted alkali treatment," Bioresource Technol. 288, 121569-121577. DOI:

10.1016/j.biortech.2019.121569

Lai, C., Yang, B., Lin, Z., Jia, Y., Huang, C., Li, X., Song, X., and Yong, Q. (2019b). "New strategy to elucidate the positive effects of extractable lignin on enzymatic hydrolysis by quartz crystal microbalance with dissipation," Biotechnol. Biofuels 12, 57-68. DOI: 10.1186/s13068-019-1402-2

Li, M., Pu, Y., and Ragauskas, A. J. (2016). "Current understanding of the correlation of lignin structure with biomass recalcitrance," Frontiers in Chemistry 4, 45. DOI: 10.3389/fchem.2016.00045

Lou, H., Zhu J., Lan, T., Lai, H., and Qiu, X. (2013). "pH-Induced lignin surface modification to reduce nonspecific cellulase binding and enhance enzymatic saccharification of lignocelluloses," Chem Sus Chem 6, 919-927. DOI: $10.1002 /$ cssc. 201200859

Lu, X., Zheng, X., Li, X., and Zhao, J. (2016). "Adsorption and mechanism of cellulase enzymes onto lignin isolated from corn stover pretreated with liquid hot water," Biotechnol. Biofuels 9, 118-129. DOI: 10.1186/s13068-016-0531-0

Meng, X., Foston, M., Leisen, J., DeMartini, J., Wyman, C., and Ragauskas, A. (2013). "Determination of porosity of lignocellulosic biomass before and after pretreatment by using Simons' stain and NMR techniques," Bioresource Technol. 144, 467-476. DOI: 10.1016/j.biortech.2013.06.091

Mosier, N., Wyman, C., Dale, B., Elander, R., Lee, Y., Holtzapple, M., and Ladisch, M. (2005). "Features of promising technologies for pretreatment of lignocellulosic biomass," Bioresource Technol. 96, 673-686. DOI: 10.1016/j.biortech.2004.06.025

Nakagame, S., Chandra R., Kadla, J., and Saddler, J. (2011). "Enhancing the enzymatic hydrolysis of lignocellulosic biomass by increasing the carboxylic acid content of the associated lignin," Biotechnol. Bioeng. 108, 538-548. DOI: 10.1002/bit.22981

Pareek, N., Gillgren, T., and Jönsson, L. (2013). "Adsorption of proteins involved in hydrolysis of lignocellulose on lignins and hemicelluloses," Bioresource Technol. 148, 70-77. DOI: 10.1016/j.biortech.2013.08.121 
Pu, Y., Zhang, D., Singh, P. M., and Ragauskas, A. J. (2008). "The new forestry biofuels sector," Biofuels Bioprod. Biorefin. 2, 58-73. DOI: 10.1002/bbb.48

Rico, A., Rencoret, J., Río, J., Martínez, A., and Gutiérrez, A. (2014). "Pretreatment with laccase and a phenolic mediator degrades lignin and enhances saccharification of Eucalyptus feedstock," Biotechnol. Biofuels 7, 6-19. DOI: 10.1186/1754-6834-7-6

Saini, J., Patel, A., Adsul, M., and Singhania, R. (2016). "Cellulase adsorption on lignin: A roadblock for economic hydrolysis of biomass," Renew. Energ. 98, 29-42. DOI: 10.1016/j.renene.2016.03.089

Samuel, R., Pu, Y., Raman, B., and Ragauskas, J. (2010). "Structural characterization and comparison of switchgrass ball-milled lignin before and after dilute acid pretreatment," Appl. Biochem. Biotechnol. 162, 62-74. DOI: 10.1007/s12010-009-8749-y

Selig, M., Viamajala, S., Decker, S., Tucker, M., Himmel, M., and Vinzant, T. (2007). "Deposition of lignin droplets produced during dilute acid pretreatment of maize stems retards enzymatic hydrolysis of cellulose," Biotechnol. Progr. 23(6), 13331339. DOI: $10.1021 / \mathrm{bp} 0702018$

Sun, S., Huang, Y., Sun, R., and Tu, M. (2016). "Strong association of condensed phenolic moieties in isolated lignins with their inhibition of enzymatic hydrolysis," Green Chem. 18, 4276-4286. DOI: 10.1039/C6GC00685J

Sun, J, Sun, X, Sun, R, Fowler, P, and Baird, M. (2003). "Inhomogeneities in the chemical structure of sugarcane bagasse lignin," J. Agric. Food Chem. 51, 6719-6725. DOI: $10.1021 / \mathrm{jf034633j}$

Teramura, H., Sasaki, K., Oshima, T., Aikawa, S., Matsuda, F., Okamoto, M., Shirai, T., Kawaguchi, H., Ogino, C., Yamasaki, M., Kikuchi, J., and Kondo, A. (2015). "Changes in lignin and polysaccharide components in 13 cultivars of rice straw following dilute acid pretreatment as studied by solution-state $2 \mathrm{D}{ }^{1} \mathrm{H}-{ }^{13} \mathrm{C}$ NMR," Plos One 10, 1-17. DOI: 10.1371/journal.pone.0128417

Wu, S., and Argyropoulos, D. S. (2003). "An improved method for isolating lignin in high yield and purity," J. Pulp. Pap. Sci. 29,235-240. DOI: 10.1023/A:1025117327970

Xu, N., Zhang, W., Ren, S., Liu, F., Zhao, C., Liao, H., Xu, Z., Huang, J., Li, Q., Tu, Y., Yu, B., Wang, Y., Jiang, J., Qin, J., and Peng L. (2012). "Hemicelluloses negatively affect lignocellulose crystallinity for high biomass digestibility under $\mathrm{NaOH}$ and $\mathrm{H}_{2} \mathrm{SO}_{4}$ pretreatments in Miscanthus," Biotechnol. Biofuels 5, 58-69. DOI: 10.1186/1754-6834-5-58

Yao, L., Yue, J., Zhao, J., Dong, J., Li, X., and Qu, Y. (2010). “Application of acidic wastewater from monosodium glutamate process in pretreatment and cellulase production for bioconversion of corn stover feasibility evaluation," Bioresource Technol. 101,8755-8761. DOI: 10.1016/j.biortech.2010.04.104

Yao, L., Yang, H., Yoo, C., Meng, X., Li, M., Pu, Y., Ragauskas, A., and Sykes, R. (2017). "Adsorption of cellobiohydrolases I onto lignin fractions from dilute acid pretreated Broussonetia papyrifera," Bioresource Technol. 244, 957-962. DOI: 10.1016/j.biortech.2017.08.024

Yao, L., Yoo, C., Meng, X., Li, M., Pu, Y., Ragauskas, A. J., and Yang, H. (2018a). “A structured understanding of cellobiohydrolase I binding to poplar lignin fractions after dilute acid pretreatment," Biotechnol. Biofuels. 11, 96-106. DOI: 10.1186/s13068018-1087-y

Yao, L., Yang, H., Yoo, C., Meng, X., Pu, Y., Hao, N., and Ragauskas, A. (2018b). "Characteristics of lignin fractions from dilute acid pretreated switchgrass and their 
effect on cellobiohydrolase from Trichoderma longibrachiatum," Front. Energy Res. 6, 1-9. DOI: 10.3389/fenrg.2018.00001

Yang, H., Xie, Y., Zheng, X., Pu, Y., Huang, F., Meng, X., Wu, W., Ragauskas, A., and Yao, L. (2016). "Comparative study of lignin characteristics from wheat straw obtained by soda-AQ and kraft pretreatment and effect on the following enzymatic hydrolysis process," Bioresource Technol. 207, 361-369. DOI:

10.1016/j.biortech.2016.01.123

Yu, Z., Gwak, K., Treasure, T., Jameel, H., Chang, H., and Park, S. K. (2014). "Effect of lignin chemistry on the enzymatic hydrolysis of woody biomass," Chem. Sus. Chem. 7, 1942-1950. DOI: $10.1002 / \mathrm{cssc} .201400042$

Yoo, C., Li, M., Meng, X., Pu, Y., and Ragauskas, A. (2017). "Effects of organosolv and ammonia pretreatments on lignin properties and its inhibition for enzymatic hydrolysis," Green Chem. 19 (8), 2006-2016. DOI: 10.1039/C6GC03627A

Zeng, J., Helms G., Gao, X., and Chen, S. (2013). "Quantification of wheat straw lignin structure by comprehensive NMR analysis," J. Agric. Food Chem. 61, 10848-10857. DOI: $10.1021 /$ jf4030486

Article submitted: January 6, 2020; Peer review completed: March 31, 2020; Revised version received and accepted: April 9, 2020; Published: May 11, 2020.

DOI: 10.15376/biores.15.3.4898-4911 